\title{
Estado da Questão sobre a Experimentação no Contexto Online: o que Dizem os Eventos da Área do Ensino de Física? what do the Events in the Physics Teaching Field Say?
}

\section{Daiane Rattmann Magalhães Pirez ${ }^{1 *}$}

Anahy Arrieche Fazio'

Franciele Pires Ruas ${ }^{1}$

Rafaele Rodrigues de Araujo ${ }^{1}$

1 Universidade Federal do Rio Grande

- FURG. Av. Itália, km 8, Bairro

Carreiros - Rio Grande - RS - Brasil.

*daianepirez@furg.br

\section{Resumo}

A pesquisa buscou compreender o Estado da Questão sobre a experimentação em Física no contexto online através de eventos organizados pela Sociedade Brasileira de Física e Associação Brasileira de Educação a Distância. Para isso, analisamos 40 artigos por meio de duas categorias: "Ferramenta didática: as potencialidades e os limites que atravessam o uso do experimento virtual e presencial no ensino de Física" e "Espaços e estratégias didáticas online na formação de professores de Física". Significamos que a integração entre recursos virtuais e reais no âmbito da modalidade presencial, a distância ou híbrida, constitui-se como um caminho para que as aulas se tornem mais interativas, cabendo ao professor utilizá-las na criação de atividades que ampliem as ações colaborativas em sala de aula.

Palavras-chave: Experimentação. Ensino online. Estado da questão. Ensino de física.

\section{(c) 0}

Recebido:04/01/2021 Aceito: 29/03/2021 Publicado:30/03/2021

\section{COMO CITAR ESTE ARTIGO}

ABNT: PIREZ, D. R. M. et al. Estado da Questão sobre a Experimentação no Contexto Online: o que Dizem os Eventos da Área do Ensino de Física? EaD em Foco, v. 11, n. 1, e1371, 2021 DOI: https://doi.org/10.18264/eadf.v11i1.1371. 


\section{Abstract}

The research aimed to understand the State of the Question of experimentation in Physics in the online context through events organized by the Brazilian Physics Society and by the Brazilian Association for Distance Education. For this, we analyzed 40 articles through two categories: "Didactic tool: the potentials and limits that cross the use of the virtual and face-to-face experiment in the teaching of Physics" and "Online teaching spaces and strategies in the training of physics teachers". We concluded that the integration between virtual and real resources is the realm of face-to-face, distance or hybrid modalities, constitutes as a way for the classes to become more interactive, leaving the teacher to use them in the creation of activities that expand collaborative actions in the classroom.

Keywords: Experimentation. Online teaching. State of the question. Physics teaching.

\section{Introdução}

Temos presenciado atualmente um acelerado desenvolvimento tecnológico com a ampliação de diversos recursos e interfaces digitais, o que tem motivado inúmeras transformações em nossa sociedade. Alunos e professores encontram-se imersos constantemente nesse mundo dito virtual. Neste sentido, os processos de ensino e de aprendizagem precisam acompanhar as transformações que vêm ocorrendo em nossa sociedade, geradas pelo desenvolvimento das tecnologias e meios de comunicação. Na área do ensino de Ciências da Natureza já é possível perceber um movimento tanto de professores, quanto de licenciandos no sentido de integrar às suas práticas, diferentes ferramentas e recursos tecnológicos.

Aliado a essa questão, temos o fato de que, para alguns sujeitos, as atividades experimentais ainda se mostram como um desafio no pensar e no fazer quando o assunto se refere ao contexto online. No entanto, Heckler et al. (2013, p.7) afirmam que o “[...] operar na experimentação em Ciências online é uma forma de superar em coletivo as inseguranças quanto a esta apropriação e linearidade dos tempos de aprendizagem".

Transpondo estes desafios, a apropriação das ferramentas tecnológicas caracteriza um cenário que vai além da instrumentação e possibilita o estudo de fenômenos da natureza num patamar epistemológico, rompendo com a ideia de experimentação com foco exclusivo na comprovação de teorias, com o uso de roteiros estanques. Com isso, fala-se numa experimentação que preza pela investigação e conta com ambientes colaborativos como meio de problematizar e dialogar sobre os saberes.

Dessa forma, explicitamos que articular a experimentação e o ensino online é emergente e que apresenta uma série de discussões no campo da Educação. Com isso, o objetivo desse artigo é compreender o Estado da Questão sobre a experimentação em Física no contexto online em eventos nacionais e internacionais das áreas do ensino de Física e da Educação a Distância. Para isso, realizamos o Estado da Questão nos eventos nacionais da área do ensino de Física organizados pela Sociedade Brasileira de Física e um evento internacional organizado pela Associação Brasileira de Educação a Distância, a fim de percebermos o que se mostra sobre discussões nessa temática na comunidade científica brasileira. 


\section{Estado da Questão: O percurso metodológico}

Para a realização da pesquisa qualitativa, a qual teve por objetivo compreender o que se mostra sobre a experimentação em Física no contexto online, utilizamos como metodologia de pesquisa e análise o Estado da Questão. Essa metodologia tem por finalidade, de acordo com Nóbrega-Thierren e Thierren (2004, p. 8): “Delimitar e caracterizar o objeto (específico) de investigação de interesse do pesquisador e a consequente identificação e definição das categorias centrais da abordagem teórico-metodológica". Com isso, nosso corpus de investigação ocorreu em eventos nacionais da área do ensino de Física, realizados pela Sociedade Brasileira de Física (SBF) e um evento internacional relacionado a Educação a Distância realizados pela Associação Brasileira de Educação a Distância (ABED). Sendo assim, foram três eventos analisados: o Encontro de Pesquisa em Ensino de Física (EPEF), o Simpósio Nacional de Ensino de Física (SNEF) e o Congresso Internacional de Educação a Distância (CIAED).

O Estado da Questão “[...] configura então o esclarecimento da posição do pesquisador e de seu objeto de estudo na elaboração de um texto narrativo, a concepção de ciência e a sua contribuição epistêmica no campo do conhecimento" (NÓBREGA-THIERREN; THIERREN, 2004, p. 9). Dessa forma, focamos nosso olhar nos eventos citados anteriormente, de maneira a buscar contribuições para a temática em questão. O período de análise desses eventos foi de 20 anos, de forma que a investigação ocorreu em eventos realizados desde o ano 2000 a 2019, com os seguintes descritores: Online; Educação a distância; Experimentação; Atividades Experimentais; Experimento.

Nesse primeiro movimento de análise, nos eventos que tinham os anais disponíveis, encontramos 263 artigos. Estes textos continham os descritores no título ou nas palavras-chave ou no resumo. No entanto, como nosso objeto de investigação se dá em torno da experimentação online no ensino de Física, após um segundo movimento de análise, ou seja, uma leitura atenta das escritas selecionadas, percebemos que alguns não se adequaram à temática pesquisada. Com isso, para a análise qualitativa restaram 40 artigos, os quais apresentamos no Quadro 1. 
Quadro 1: Artigos selecionados por evento com a codificação

\begin{tabular}{|c|c|c|c|}
\hline Evento & Ano & Autor(es) & Código \\
\hline \multirow{22}{*}{ SNEF } & \multirow{4}{*}{2017} & SANTOS, J. S. dos et al. & A1 \\
\hline & & GOMES, C. et al. & $\mathrm{A} 2$ \\
\hline & & EVANGELHO, B. V do; SANTOS, R. C. M. & $\mathrm{A} 3$ \\
\hline & & SIM, A. A. do; MONTEIRO, M. A. A. & A4 \\
\hline & \multirow{6}{*}{2015} & XAVIER, A. P.; VERTCHENKO, L.; AMANTES, A. & A5 \\
\hline & & MORO, F. T.; NEIDE, I. G.; VETTORI, M. & A6 \\
\hline & & IWAMOTO, H. K. S.; CAETANO, T. C.; SILVA, A. P. da & A7 \\
\hline & & SILVA, J. C. et al. & A8 \\
\hline & & LEAL, A. C. da S. et al & A9 \\
\hline & & SALES, G. L.; LEITE, E. A. M; VASCONCELOS, G. H. L. & A10 \\
\hline & \multirow{5}{*}{2013} & MONTEIRO, M. A. A. et al. & A11 \\
\hline & & SILVA, N. C. da & $\mathrm{A} 12$ \\
\hline & & DUTRA, L. de. M; BARROSO, M. F. & A13 \\
\hline & & MONTEIRO, J. C. B. et al. & A14 \\
\hline & & NEVES, J. A. et al. & A15 \\
\hline & \multirow{2}{*}{2009} & LOPES, R. P. et al. & A16 \\
\hline & & PESSANHA, M. C.R.; COZENDEY, S. G.; SOUZA, M. de O. & A17 \\
\hline & \multirow{2}{*}{2007} & SILVA, T. da. & A18 \\
\hline & & AGUIAR, M. S.; CASTRO, R. M. de & A19 \\
\hline & 2005 & GAMA, C. F.; PAZÊTO, F.; COUVEIA, R. C. & A20 \\
\hline & \multirow{2}{*}{2003} & SOUZA, G. L. de et al. & $\mathrm{A} 21$ \\
\hline & & KOEHLER, L. F.; MAZER, H.; BRINATTI, A. M. & A22 \\
\hline \multirow{14}{*}{ EPEF } & \multirow{3}{*}{2018} & NEIDE, I. G.; GAMA JÚNIOR, R. C. & A23 \\
\hline & & ALVES, N. F.; NEIDE, I. G. & A24 \\
\hline & & PONTONE JUNIOR, R.; PAULA, H. de F. e & A25 \\
\hline & 2016 & SENA, M.; SILVA, R.; MARTINS, A. & A26 \\
\hline & \multirow{2}{*}{2014} & CAETANO, T. C.; SILVA, A. P. da; MOREIRA, C. C. & A27 \\
\hline & & DUARTE, M.; JAMMAL, N.; JUNIOR, E. da C. & A28 \\
\hline & \multirow{3}{*}{2012} & HEIDEMANN, L. A.; ARAUJO, I. S.; VEIT, E. A. & A29 \\
\hline & & AGUIAR JUNIOR. O; VILLANI, C. E. P. & A30 \\
\hline & & SILVA, C. F. da et al. & A31 \\
\hline & \multirow{3}{*}{2008} & SILVA, M. J. V. T. da; ANGOTTI, J. A. P.; MION, R. A. & A32 \\
\hline & & STEIN-BARANA, A. C. de M.; LOPES, D. P. M. & A33 \\
\hline & & SILVA, T. da; BARROSO, M. F. & A34 \\
\hline & \multirow{2}{*}{2004} & CARVALHO, D. L. de; DUARTE, J. L. M.; PACCA, J. L. de A. & A36 \\
\hline & & SCHUCK, A. F.; SERRANO, A. & A37 \\
\hline \multirow{3}{*}{ CIAED } & 2015 & MOREIRA, R. M.; MANTILLA, S. P. S. & A38 \\
\hline & 2005 & MENDES, M. A.; FIALHO, F. A. P. & A39 \\
\hline & 2001 & SOUZA, C. P. de; COSTA FILHO, J. T. & A40 \\
\hline
\end{tabular}


No Quadro 1, explicitamos o segundo movimento de análise realizada, em que a partir do corpus inicial destacamos os artigos que discutem de alguma forma a experimentação online no ensino de Física. Com isso, realizamos novamente a leitura atenta dos 40 artigos selecionados na busca de relações, em um processo de categorização. De acordo com Nóbrega-Thierren e Thierren (2004, p. 11) “[...] é precisamente esse processo e o material/texto produzido nessa fase que fornecem os elementos para identificar e definir os referenciais e as categorias imprescindíveis à análise dos dados no enfoque desejado".

Nessa perspectiva, com o processo de categorização, encontramos duas categorias que expressam as relações dos artigos analisados, sendo essas: "Ferramenta didática: as potencialidades e os limites que atravessam o uso do experimento virtual e presencial no ensino de Física" e "Espaços e estratégias didáticas online na formação de professores de Física". A distribuição dos artigos nessas duas categorias está expressa no Quadro 2.

Quadro 2: Distribuição dos artigos por categoria

\begin{tabular}{|c|c|}
\hline $\begin{array}{l}\text { Ferramentas didáticas: as potencialidades e os limites que } \\
\text { atravessam o uso do experimento virtual e presencial no } \\
\text { ensino de Física }\end{array}$ & $\begin{array}{l}\text { Espaços e estratégias didáticas online na formação de pro- } \\
\text { fessores de Física }\end{array}$ \\
\hline $\begin{array}{l}A 1, A 2, A 3, A 4, A 5, A 6, A 7, A 8, A 9, A 11, A 12, A 13, A 15, A 16, \\
A 18, A 19, A 21, A 22, A 23, A 26, A 27, A 28, A 32, A 34, A 35, A 36, \\
A 37, A 38, A 39, A 40\end{array}$ & $A 10, A 14, A 17, A 20, A 24, A 25, A 29, A 30, A 31, A 33$ \\
\hline
\end{tabular}

Fonte: elaborado pelas autoras

Conforme apresentamos no Quadro 2, os artigos selecionados foram distribuídos em duas categorias emergentes da análise. Com isso, realizaremos a discussão dos resultados em que percebemos na primeira categoria "Ferramentas didáticas: as potencialidades e os limites que atravessam o uso do experimento virtual e presencial no ensino de Física" uma gama de ferramentas, artefatos didáticos e metodologias abordados em diferentes contextos teórico-práticos. Buscamos, também, nessa categoria as potencialidades e as limitações, a partir das experiências relatadas nos trabalhos, que envolvem o uso das diferentes formas de experimentação.

Na segunda categoria "Espaços e estratégias didáticas online na formação de professores de Física" discutiremos como a formação inicial e continuada de professores necessita de espaços que oportunizem a discussão, a reflexão e o debate de temas que perpassam à docência, culminando na melhoria da prática e consequentemente, do ensino e da aprendizagem. Sendo assim, no próximo tópico traremos essas discussões permeadas nestas temáticas emergentes do processo da análise do Estado da Questão.

\section{Discussão dos Resultados}

\subsection{Espaços e estratégias didáticas online na formação de professores de Física}

Pensando nos espaços formativos enquanto potencial pedagógico, a experimentação pode ser uma aliada estratégia didática no contexto do ensino das Ciências Naturais, em especial da Física. Numa perspectiva que vai além da comprovação da teoria na prática, necessita assumir nos sujeitos o papel de desenvolver diferentes habilidades, como a escrita, a observação, a indagação, a proposição de hipóteses, a análise, dentre outras ações coletivas (COSTA e GALEGO, 2018).

No âmbito de cursos de formação continuada ou inicial cuja oferta ocorra na modalidade da educação a distância online, destacamos, conforme o trabalho de A33, a promoção da inclusão digital de professores que carecem desta, de modo que, além de propiciar a inserção em espaços formativos, se constitua 
enquanto ferramenta didática. No decorrer do curso de formação, a realização de práticas experimentais de Física pelos professores dos anos iniciais, a partir de materiais de baixo custo presentes em suas residências, contribuiu para romper com a ideia de que um laboratório de Ciências/Física é apenas aquele constituído por equipamentos sofisticados. Com isso a tecnologia digital tornou-se aliada na socialização e ampliação do conhecimento, algo ainda válido nos dias atuais. Desse modo, o computador enquanto ferramenta tecnológica, além de fortalecer os saberes docentes, beneficia os estudantes, uma vez que estarão envolvidos com novas propostas (OLIVEIRA e FREIRE, 2016).

Seguindo na linha dos computadores, porém agora com foco nos softwares, em A17, observa-se que a experimentação em cursos de educação a distância online pode ser uma alternativa, evitando recorrer a aulas presenciais para a realização desse tipo de atividade. Através da internet, utilizou-se um software para conduzir o procedimento experimental "radiação luminosa e corpos claros e escuros", permitindo ao servidor de controle o acompanhamento dos usuários que estavam fora da universidade, tanto na coleta, quanto no envio de dados. Como foi exposto, houve a possibilidade dos usuários interagirem conectados ao sistema. Em Hoffmann (2017), entendemos que a utilização de programas e softwares potencializa a exploração de experimentos, pois através da animação e simulação, idealiza-se um fenômeno da natureza. Assim, também se constituem os programas e softwares, como experimento que se utilizam de conhecimentos científicos a partir de desenvolvimento tecnológico.

Em algumas escritas percebemos que as atividades experimentais reais atreladas ao uso de simulação computacional, laboratório, produção audiovisual e atividade virtual aparecem como estratégia didático-metodológica de mediação no ensino de Física. Destas, em A29 emerge que o surgimento dos laboratórios virtuais deve ser visto como complementar aos laboratórios físicos, no sentido de que um não deva substituir o outro, mas somar enquanto recurso disponível ao ensino de Física e sem prejuízo à aprendizagem. Com isso, é fundamental considerar os objetivos e pretensões do professor acerca do desenvolvimento de sua aula, bem como as habilidades e competências que gostaria de evocar em seus alunos. Nesse sentido, o uso de roteiros "receita de bolo", que impossibilitam a reflexão sobre o conteúdo ou excessivamente abertos, que sobrecarregam cognitivamente os estudantes ou que culminem com a chegada a uma "resposta certa", desprovidos de contextualização, devem ser evitados.

A favor disso, Tori (2010) enfatiza que a utilização de recursos virtuais também pode ser um suporte a atividades presenciais, experimentação real e virtual, por exemplo. Destarte, aulas presenciais com comunicação via ambientes virtuais de aprendizagem ou recursos virtuais, com a presença física de um professor, agregam potencial para a cooperação entre o virtual e o presencial, principalmente ao incorporar práticas colaborativas que motivem e envolvam os sujeitos através de tecnologias digitais de comunicação.

Nessa lógica, a escrita de A24, após pesquisa bibliográfica investigou a integração de experimentos reais e virtuais como estratégia metodológica para o ensino da Óptica Geométrica. Cabe destacar a escassez de produções nesse viés, principalmente com foco no ensino do tema supramencionado, emergindo apenas o uso separado destas estratégias. No entanto, os autores reforçam que a articulação destas atividades auxilia não apenas no desenvolvimento científico, mas no tecnológico e cultural dos estudantes.

Leiria e Mataruco (2015) inferem que enquanto estratégia metodológica as atividades experimentais, reais ou virtuais, necessitam de fundamentação pedagógica e epistemológica, no sentido de que proporcionem relação entre os aspectos naturais e artificiais que permeiam um fenômeno, favorecendo o espírito investigativo dos estudantes. Seguindo nessa perspectiva, na escrita de A25 a focalização do estudo está na frequência e na utilização de aplicativos de simulação sobre fenômenos ondulatórios numa sala de aula de Física de uma escola técnica de Ensino Médio, bem como a relevância nas atividades mediadas por outros recursos. Observou-se que os aplicativos estavam aliados ao uso de recursos mediacionais, como experimentos com manipulação de artefatos reais. Ressaltamos que foi atribuída similar importância por parte do professor, que os utilizou de forma integrada e com a mesma frequência nas aulas. 
Um dos estudos presentes em A30 versa pelo entendimento de como professores supervisores e licenciandos de um grupo do Programa Institucional de Bolsas de Iniciação à Docência - PIBID de Física examinam as possibilidades de uso da experimentação e simulação no ensino da área, a partir da experiência no programa. Antes de uma Mostra Interativa, a concepção dos participantes não se mostrou favorável ao uso da simulação, pois eles acreditavam correr o risco de substituir a experimentação real por um recurso que poderia apresentar limitações na forma de representar a realidade, algo que posteriormente se modificou, isto é, no geral os participantes compreenderam que ambas são formas distintas de se enxergar um fenômeno, mas passíveis de complementação. Além disso, constituem recurso mediacional no resgate do aluno como sujeito ativo de sua aprendizagem.

Na pesquisa de A31, intenta-se identificar se cinco escolas públicas da região de Rondônia utilizam experimentos virtuais e reais que favoreçam uma aprendizagem significativa com base no contexto dos alunos. Para isso, realizou-se um levantamento com professores, alunos e administrativos da educação. Por ocasião, ficou evidenciado que os professores, em sua maioria, não integram e resistem à utilização de recursos pedagógicos virtuais. As escolas, embora deficitárias, apresentam salas de laboratório de Ciências e de Informática, porém não são vinculados ao estudo e pesquisa na área de Física, demonstrando que os conteúdos trabalhados seguem uma vertente mais tradicional. Esta resistência e insegurança apresentada por docentes quanto ao uso de tecnologias e recursos virtuais, decorre da falta de oportunidade e de formações que lhes propiciem refletir e problematizar numa abordagem detalhada sobre situações de uso, ressaltando os benefícios para o ensino e aprendizagem (OLIVEIRA; MOURA; SOUZA, 2015).

A pesquisa de A20 expõe que a experimentação aparece atrelada à produção de vídeos experimentais instrucionais no contexto da formação de professores de Física, isto é, estudantes partícipes de um projeto de iniciação científica incumbiram-se da produção de materiais audiovisuais, objetivando disponibilizar aos novos professores que não possuíam experiência com laboratórios. Com tais atividades, percebeu-se o crescimento intelectual do grupo, que contou com a instrução do professor orientador a respeito de iluminação, enquadramento, dentre outros aspectos para uma produção desse tipo. Com a discussão realizada na pesquisa, explicita-se que o audiovisual passou a ser visto como uma ferramenta que com o som e imagens cativa a atenção do aluno e auxilia no ensino de Física, aumentando as possibilidades de transportá-lo até situações do seu cotidiano.

Pereira et al. (2011) mencionam que as demonstrações experimentais em formato audiovisual se constituem diferentes em relação à abordagem tradicional em laboratório, já que, neste caso, os estudantes podem de forma recursiva-reflexiva, e não linear, pesquisar, levantar conceitos, criar a situação experimental, testar, modificar e verificá-la sempre que necessário. E, mesmo denotando aos alunos responsabilidade no decorrer da produção, devem contar ainda com o professor orientando o processo.

Em A14 o foco está nos efeitos do AVA sobre a motivação e aprendizagem dos estudantes de uma escola pública de Ensino Médio a respeito da disciplina de Física. Além de o professor utilizar experimentos, simulações, textos e vídeos como estratégia metodológica, utilizou ainda da ferramenta fórum a fim de possibilitar a interação entre os estudantes. Tais aulas ocorridas no espaço do laboratório de informática da escola, quinzenalmente, eram intercaladas com aulas presenciais. Concluiu-se que a maioria dos estudantes considerou que as atividades virtuais contribuíram na compreensão dos fenômenos estudados, em contraponto a uma minoria, que teve dificuldades e achou cansativa a dinâmica de aulas online, dificultando o seu desempenho. Neste trabalho fica evidente a importância de que a escolha das ferramentas e objetos de aprendizagem seja feita pensando no alcance da aprendizagem por meio da interação entre alunos e professor, e dos alunos com os objetos e ferramentas disponibilizados no ambiente.

Heckler, Fazio e Ruas (2020) destacam que o surgimento da web 2.0 permeou-nos por plataformas, ambientes virtuais de aprendizagem, interfaces/ferramentas como simuladores, aplicativos, vídeos, animações, dentre outros recursos, nos mostrando outra face do laboratório de Ciências. Neste laboratório, as ações na experimentação modificam-se, contando mais com a colaboração entre os sujeitos, geografi- 
camente distantes ou não, que se tornam coautores no processo. Quando intencionada para o contexto online, a experimentação também pode assumir um enfoque colaborativo e dialógico, e por meio de interfaces/ferramentas da web 2.0, constituir um cenário que preze pela mediação colaborativa na busca por aperfeiçoar compreensões em torno dos temas de estudo (HECKLER, 2014).

A partir da análise realizada, verificamos as inúmeras possibilidades de integração de recursos virtuais e reais que permeiam as estratégias didáticas e os espaços formativos da docência no que tange a experimentação, não atribuindo maior importância a um ou outro. Com isso, seja na modalidade online, presencial ou híbrida, a combinação e a cooperação de tais recursos e atividades oportuniza agregar o que de melhor as constitui, de modo que se convergirem no viés da interação, da colaboração, do diálogo e da troca de saberes, estarão cumprindo o seu papel no ensino e na aprendizagem.

\subsection{Ferramentas didáticas: as potencialidades e os limites que atravessam o uso do experimento virtual e presencial no ensino de Física}

Nesta categoria, além dos espaços e estratégias didáticas, se fez presente uma discussão sobre a grande variedade de ferramentas, artefatos didáticos e metodologias, sendo estes abordados em diferentes contextos teórico-práticos que serão discutidos a seguir. Para além da identificação e compreensão desses contextos, buscamos as potencialidades e as limitações, a partir das experiências relatadas nos trabaIhos, que envolvem o uso das diferentes formas de experimentação.

A dificuldade dos estudantes e altos índices de reprovações (A17, A20), o uso de metodologias voltadas a exposição do conteúdo (A6, A17, A20), a memorização de fórmulas (A20), a falta de relação dos conteúdos com o cotidiano (A4) e a falta de motivação e interesse em relação a Física (A27) são algumas evidências apontadas pelos autores que os motivam a refletir acerca dos aspectos teórico-práticos do ensino de Física. Outro fator apontado nos trabalhos é o alto grau de abstração dos conteúdos de Física (A5, A19, A20, A23, A25, A37 e A38), assim, a experimentação real, experimentação remota, laboratórios virtuais, uso de simulações e de simuladores como ferramentas didáticas emergem para potencializar e repensar as metodologias de ensino e de aprendizagem em Física.

É interessante afirmar que a preocupação com o ensino de Física, suas metodologias e as relações de ensino e de aprendizagem são temáticas recorrentes nas pesquisas em educação no cenário nacional e internacional. Neste último, estudos recentes apontam a falta de laboratórios bem equipados (COFFIE; FREMPONG; APPIAH, 2020; SOUZA; MACHADO; SANTOS, 2020), a falta de interesse dos estudantes e motivação dos professores (SOUZA; MACHADO; SANTOS, 2020) como fatores que continuam desafiando as relaç̃̃es de ensino e de aprendizagem em Física. No Brasil, além dos motivos apontados pelos trabalhos analisados, estudos recentes de Lima (2019) e Cardoso et al. (2020), discutem, para além das questões de infraestrutura, a falta de incentivo à capacitação do profissional docente para elaborarem e realizar atividades práticas e, por esse motivo, apresentam dificuldades em desenvolver planos de aula que incluam essas atividades.

Contudo, assumida a importância da realização de experimentos no ensino de Física, os autores apontam motivos para que ainda haja ausência dessas atividades na rede básica e ensino superior, são eles: falta de infraestrutura (A4, A14, A34), os custos dos laboratórios (A17, A39), tempo de duração de alguns experimentos (A34), carência de materiais (A14, A34), carga horária insuficiente do professor (A4) e a falta de técnicos de laboratório (A14). Por esses motivos, A12 aborda como alternativa o experimento remoto em laboratórios que transcendem o espaço físico das instituições de ensino, nas suas variedades e contextos.

Nesse sentido, o uso das ferramentas didáticas no contexto online, emerge como importante recurso para sanar essas problemáticas em relação ao ensino de Física. Alguns trabalhos propõem o uso da experimentação através de laboratórios virtuais enquanto outros propõem o uso de laboratórios remotos. Os 
laboratórios remotos podem ser controlados remotamente pelo estudante, desde que o artefato ofereça ao estudante uma interface que permita que o experimento seja controlado a distância, sem a necessidade presencial do estudante no laboratório (AMARAL et al., 2011). Exemplificamos o uso de laboratórios remotos por A40 ao propor o LabNet, que é um laboratório de acesso remoto que permite a realização de experimentos via internet. A proposta da experimentação remota pela internet também é feita por A7 com o uso do Arduino e construção de interface assistida em um WebServer. Ambos apontam como uma potencialidade a universalização do laboratório, com poucos recursos, sem a necessidade de construção de diversos materiais didáticos. Ainda segundo Amaral e colaboradores (2011), de forma diferente, os estudantes em laboratórios virtuais interagem com modelos, representações do ambiente de laboratório real possibilitado pelas representações computacionais da realidade. Alguns exemplos dessas simulações serão apresentados nos parágrafos seguintes.

Apesar da convicção unânime de que o uso das tecnologias para o ensino de Física e a realização das atividades experimentais são importantes recursos para melhorar as relações de ensino e de aprendizagem, alguns autores apontam fragilidades. A13, por exemplo, expressa que os laboratórios reais possuem maior gama de equipamentos e que o experimento virtual é mais solitário, considerando que a experimentação aconteceria entre o usuário e o computador. Além dos aspectos relacionados ao manuseio dos equipamentos, A39 afirma que é preciso haver dosagem no uso de softwares simuladores, também, pelo fato de ser um sistema onde há controle total das variáveis, evitando-se danos e imperfeições e gerando insegurança e indeterminação em relação a situações práticas reais. Ademais, aponta que a aplicação de ferramentas virtuais substituindo experimentos reais retrata apenas uma situação genérica das situações reais. Assim sendo, o aluno teria uma ideia falsa de domínio de conteúdo.

Outras fragilidades são apontadas por A28, em que argumenta sobre a impossibilidade da interação manual entre os usuários e o experimento, afirmando que essa carência pode limitar a compreensão do fenômeno observado e, segundo A38, teria dificuldade de transferir o conhecimento para outras situações similares. A5 e A14 constatam que as dificuldades dos estudantes estão relacionadas não apenas em relação aos artefatos em si, mas também em relação aos comandos, descrição das atividades e compreensão das guias de atividade experimental e a comunicação do observado. Apesar dessas fragilidades, muitos trabalhos defendem o uso da simulação como forma de representar fenômenos que não são vistos em experimentações reais.

O ensino de Física Moderna (A37 e A23) e os conhecimentos astronômicos (A37) são tópicos discutidos pelo seu grau de abstração. Em A37, a ideia é a de que os estudantes consigam compreender objetos quânticos e conceitos associados à dualidade onda-partícula, usando o simulador com seu referido roteiro. A23 propõe o desenvolvimento de um software capaz de reproduzir um experimento envolvendo a Lei de Stefan-Boltzmann para a radiação de corpo negro, comumente realizado em laboratório de Física Moderna. Nestes casos, o computador passa a ser o coadjuvante no processo de ensino e de aprendizagem enquanto o estudante garante o seu protagonismo.

O contexto do ensino a distância é apresentado por outros trabalhos, os quais consideram que o uso de simuladores online pode suprir a necessidade dos experimentos práticos em cursos à distância. A38 sugere o uso de simuladores na $\mathrm{EaD}$ e, no seu trabalho, exemplifica o conteúdo de energia considerando que o simulador favoreceu os estudantes a compreenderem aspectos que não são identificados no experimento real, como por exemplo, princípio de conservação de energia.

Com a ideia de complementar o aprendizado de um conceito, A17 propõe duas situações de aprendizagem, uma real e outra virtual. Percebe-se que alguns aspectos se tornam observáveis quando representados no virtual, enquanto no real os estudantes apenas conseguiriam visualizar os efeitos, que são consequência dos processos observados. Portanto, considera-se que o uso integrado das simulações e dos experimentos reais pode suprir algumas fragilidades. Como A16 aponta, essa integração deve fazer parte de um planejamento mais amplo, com o uso de módulos de aprendizagem que utilizem softwares, 
como o Modellus e simuladores como os do PhET.

Outras fragilidades em relação ao uso exclusivo de simulações podem ser sanadas, segundo A39, com a realização de experimentos reais inicialmente, assim os simuladores teriam o papel de reforçar os entendimentos sobre o fenômeno observado no experimento real. Os simuladores do PhET também são apontados por A3, A5 e A6 como de grande potencial quando aplicados a sequências didáticas de Física e atividades investigativas que combinem os simuladores com experimentos reais.

Alguns pontos positivos do uso integrado são apontados por A5, em que afirma que combinar os experimentos virtuais e reais permite a obtenção de dados mais detalhados e precisos, que só seriam possíveis com o uso de aparelhos muito sofisticados. Mas, para além das vantagens relacionadas a aspectos instrumentais, A12 criou uma proposta para a discussão de movimento de projéteis, a qual os estudantes poderiam interagir entre si, com a simulação computacional e com a experiência real e, nesse contexto, aponta a importância do papel do professor na mediação da atividade integrada.

O uso de ambientes hipermídia é defendido por A37 e A38, isto é, ambientes que possibilitam recursos de pesquisa ágeis, abordagem de temas de maneira mais abrangente e aumentam as condições para a participação ativa, uma vez que os estudantes interagem com os conteúdos por meio de simulações, jogos, vídeos, imagens, textos e outros recursos. A33 e A39 afirmam que o papel do professor é permitir aos educandos condições de se conscientizarem com as informações que interagem, essa riqueza de informações e possibilidades garante maior autonomia do estudante durante o processo.

Em recente estudo, Ruas et al. (2020), apontam que os espaços de formação online são um meio para possibilitar o trabalho colaborativo e articulado dos sujeitos. Assim, é preciso o desenvolvimento de propostas que viabilizem a interpretação e representação dos fenômenos em vista a construção de fenômenos explicativos. Reconhecendo a importância da experimentação como forma de problematizar fenômenos do cotidiano, A4 sugere o uso das TIC e reitera a importância do professor como mediador no processo de aprendizagem, considerando que essas atividades favorecem a interação entre estudantes e o professor. Heckler, Fazio e Ruas (2020) também apontam a interação como um fator importante no desenvolvimento de projetos investigativos experimentais da EaD, onde incentivam a promoção de projetos experimentais investigativos aliados a recursos tecnológicos que promovam ambientes interativos que incitem a cocriação e a coautoria. Nesse âmbito, outros trabalhos também transcendem as barreiras da experimentação e voltam seus olhares para as metodologias em torno destas.

Defendendo o uso das tecnologias da informação e comunicação - TIC, A33 acredita que o material didático digital pode proporcionar a interatividade para além do caráter apenas informacional. Para tal, é preciso uma interface que propicie a interatividade e a coautoria. Assim, o uso de ferramentas tecnológicas para a realização de atividades experimentais deve ser incentivado seguindo algumas pistas, como fomentado pelas emergências acima, dentre elas, é preciso selecionar ferramentas que tenham interface amigável e de fácil interação, que sejam contextuais de linguagem acessível e adequadas a realidade dos estudantes.

Para além da ferramenta, é preciso que o professor seja agente mediador, pense em abordagens metodológicas que incitem os estudantes a interagirem com as ferramentas e entre si, e que estimulem o caráter investigativo e sua autonomia. Dessa forma, a metodologia escolhida poderá englobar outros recursos hipermídia para complementarem o uso da simulação e, na disposição de estrutura para a realização de experimentos práticos, estes podem estar associados ao uso de simulações.

\section{Considerações Finais}

A partir das análises realizadas neste estudo, que tiveram por finalidade compreender o que se mostra sobre a experimentação em Física no contexto online, significamos que ao permear e constituir espaços 
formativos que versem pela inclusão digital, reflexão e problematização de estratégias didático-metodológicas online, o professor terá mais oportunidades de agregar a experimentação online em sua prática pedagógica. Sendo assim, constitui-se de uma forma de reduzir a resistência e a insegurança que por vezes permeia o uso de tecnologias e recursos virtuais.

Constatamos que a experimentação online através de diferentes recursos - simulação computacional, laboratório virtual, atividade virtual e produção audiovisual - constitui potencial para o desenvolvimento de ações mais colaborativas entre os sujeitos. Suas potencialidades atravessam o uso da experimentação e através dos recursos hipermídias podem-se criar atividades investigativas que utilizem diversos objetos digitais que incentivem a autonomia, cocriação e interatividade dos estudantes.

Reitera-se que os trabalhos apontam para o desenvolvimento de novas simulações com interfaces aprimoradas e que possam estar cada vez mais conectadas com as diferentes realidades. Ao incorporá-la em sua prática pedagógica, o professor versará pela motivação dos sujeitos, envolvimento entre si e com os recursos, favorecendo o espírito investigativo dos mesmos, sendo assim, tem papel fundamental na proposição das atividades, organização e orientação do processo investigativo do estudante, seja este em ambientes online ou presenciais.

Aliado a isso, compreendemos que a integração entre recursos virtuais e reais no âmbito da modalidade presencial, a distância ou híbrida constitui um caminho para que as aulas se tornem mais interativas, denotando a cada uma importância e complementaridade. Ao professor, caberá utilizar destas estratégias didático-metodológicas na criação de dinâmicas e atividades que envolvam discussões entre os alunos, de modo a ampliar as ações colaborativas em sala de aula.

\section{Referências}

AGUIAR, M. S.; CASTRO, R. M. de. Atividades experimentais e novas tecnologias nas disciplinas de Física no Ensino Médio. Anais do XVII Simpósio Nacional de Ensino de Física. São Luís - MA. 2007. Disponível em: https://sec.sbfisica.org.br/eventos/snef/xvil/atas/resumos/T0525-1.pdf. Acesso em: 15 jul. 2020.

AGUIAR JÚNIOR, O. G.; VILLANI, C. E. P. Experimentos e simulações como recursos mediacionais no ensino de Física: reflexões no curso de experiência de formação docente no PIBID/UFMG. Anais do XIV Encontro de Pesquisa em Ensino de Física. São Sebastião - SP. 2012. Disponível em: https://sec.sbfisica.org. br/eventos/epef/xiv/sys/resumos/T0314-1.pdf. Acesso em: 15 jul.2020.

AGUIAR, M. D. et al. Teacher malaise in physics teaching: perspectives and challenges. Research, Society and Development, v. 9, n. 6, p. e106963265, 2020.

ALVES, N. F.; NEIDE, I. G. A Integração de atividades experimentais e computacionais para o ensino de Física: uma possível estratégia para o ensino de Óptica Geométrica. Anais do XVII Encontro de Pesquisa em Ensino de Física. Campos do Jordão - SP. 2018. Disponível em: https://sec.sbfisica.org.br/eventos/epef/xvii/ programa/trabalhos.asp?sesld=39. Acesso em: 15 jul. 2020.

AMARAL, É. et al . Laboratório virtual de aprendizagem: uma proposta taxonômica. RENOTE-Revista Novas Tecnologias na Educação, v.9, n.2, 2011.

BORGES, M. C. Formação inicial e continuada no PIBID - Experiências entre atores da Educação Básica e Superior. Anais do XVII ENDIPE. Fortaleza - CE. 2014.

CAETANO, T. C.; SILVA, A. P. da; MOREIRA, C. C. Desenvolvimento de experimentos de acesso remoto para o ensino de Física: uma investigação sobre as potencialidades do experimento anel de Thomson. XV Encontro de Pesquisa em Ensino de Física. São Sebastião - SP. 2014. Disponível em: http://www.sbfisica. org.br/ epef/xv/. Acesso em: 15 jul. 2020. 
CARDOSO G. F.; SILVA, A. C.; VILARDI, L. Os Desafios na Utilização do Laboratório de Ensino de Ciências pelos professores de Ciências da Natureza. Revista Insignare Scientia - RIS, v. 3, n. 2, p. 274-291, 24 ago. 2020.

CARVALHO, D. L. de; DUARTE, J. L. M.; PACCA, J. L. de A.Um curso a distância sobre eletromagnetismo:o planejamento e o processo de aprendizagem. IX Encontro de Pesquisa em Ensino de Física. Jaboticabaus - MG. 2004. Disponível em: https://sec.sbfisica.org.br/eventos/epef/ix/. Acesso em: 15 jul. 2020.

COFFIE, I. S.; FREMPONG, B. B.; APPIAH, E. Teaching and Learning Physics in Senior High Schools in Ghana: The Challenges and the Way Forward. Advances in Research, v. 21, n.3, p. 35-42, 2020.

COSTA, S. C.; GALEGO, L. G. C. Experimentação e formação inicial docente em Ciências no PIBID: relato de experiência. Revista Iniciação \& Formação Docente, vol.5, n.1, p.1-14, 2018.

DUARTE, M.; JAMMAL, N.; JUNIOR, E. da C. Atividades experimentais de bancada e simulações computacionais: percepções dos alunos sobre realidade. XV Encontro de Pesquisa em Ensino de Física. São Sebastião - SP. 2014. Disponível em: http://www.sbfisica.org.br/ epef/xv/. Acesso em: 15 jul. 2020.

DUTRA, L. de. M; BARROSO, M. F. O uso de experimentos como ferramenta de ensino e aprendizagem: estudo de um caso. Anais do XX Simpósio Nacional de Ensino de Física. São Paulo - SP. 2013. Disponível em: https://sec.sbfisica.org.br/eventos/snef/xx/sys/resumos/T0552-1.pdf. Acesso em: 15 jul. 2020.

EVANGELHO, B. V do; SANTOS, R. C. M. Anais do XXII Simpósio Nacional de Ensino de Física. São Carlos - SP. 2017. Disponível em: https://sec.sbfisica.org.br/eventos/snef/xxii/sys/resumos/T0594-1.pdf. Acesso em: 15 ago. 2020.

GAMA, C. F.; PAZÊTO, F.; COUVEIA, R. C. Vídeo instrucional - montagem de experimentos. Anais do XVI Simpósio Nacional de Ensino de Física. Rio de Janeiro - RJ. 2005. Disponível em: https://sec.sbfisica. org.br/eventos/snef/xvi/cd/resumos/T0641-1.pdf. Acesso em: 23 ago. 2020.

GOMES, C. et al. Desenvolvimento de um app android para auxiliar a confecção de experimentos alternativos para o ensino de Física. Anais do XXII Simpósio Nacional de Ensino de Física. São Carlos - SP. 2017. Disponível em: https://sec.sbfisica.org.br/eventos/snef/xxii/sys/resumos/T1946-1.pdf. Acesso em 15 ago. 2020.

GOUVEIA, R. C.; GAMA, C. F.; PAZÊTTO, F. Vídeo Instrucional - Montagem de Experimentos. Anais do XVI Simpósio Nacional de Ensino de Física. Rio de Janeiro-RJ. 2005. Disponível em: https://sec.sbfisica. org.br/eventos/snef/xvil. Acesso em: 2. dez. 2019.

HECKLER, V. et al. A experimentação em Ciências online envolve sujeitos em pesquisa-formação ao operar objeto aperfeiçoável imersos na linguagem. Atas do VIII ENPEC. Campinas - SP. 2011. Disponível em: http://abrapecnet.org.br/atas_enpec/viiienpec/resumos/R0862-1.pdf. Acesso em 13 jul. 2020.

HECKLER, V. Experimentação em Ciências na EaD: indagação online com os professores em AVA.2014. 242 p. Tese (Doutorado em Educação em Ciências). Programa de Pós-Graduação em Educação em Ciências: Química da Vida e Saúde, Universidade Federal do Rio Grande, Rio Grande, 2014.

HECKLER, V.; FAZIO, A. A.; RUAS, F. P. Investigação com Atividades Práticas Experimentais na formação com professores geograficamente distantes. Journal of Research and Knowledge Spreading, v. 1, n.1, p.1-12, 2020.

HEIDEMANN, L. A.; ARAUJO, I. S. ; VEIT, E. A. Experimentos empíricos versus simulações computacionais: uma controvérsia no ensino de Física. Anais do XIV Encontro de Pesquisa em Ensino de Física. Maresias-SP. 2012. Disponível: http://www.sbfisica.org.br/ epef/xiv/. Acesso em: 15 jul. 2020. 
HOFFMANN , J. L. O panorama de uso da experimentação no ensino da Física em municípios da região oeste do Paraná: uma análise dos desafios e das possibilidades. 2017. 198 p. Dissertação (Mestrado em Educação). Programa de Pós-Graduação Stricto Sensu em Educação, Universidade Estadual do Oeste do Paraná, Cascavel, 2017.

IWAMOTO, H. K. S.; CAETANO, T. C.; SILVA, A. P. da; Desenvolvimento de um experimento remoto para o ensino de física: ondas estacionárias. Anais do XXI Simpósio Nacional de Ensino de Física. Uberlândia - MG. 2015. Disponível em: https://sec.sbfisica.org.br/eventos/snef/xxi/sys/resumos/T1050-1.pdf. Acesso em: 5 ago. 2020.

KOEHLER, L. F.; MAZER, H.; BRINATTI, A. M. Lei de Stefan-Boltzmann: uma experiência virtual. Anais do XV Simpósio Nacional de Ensino de Física. Curitiba - PR. 2003. Disponível em: https://sec.sbfisica.org. br/eventos/snef/xv/. Acesso em: 22 jul. 2020.

LEAL, A. C. da S. et al. Utilização de simulação computacional, experimento e intermediação do professor no ensino de movimento de projéteis para o Ensino Médio. Anais do XXI Simpósio Nacional de Ensino de Física. Uberlândia - MG. 2015. Disponível em: https://sec.sbfisica.org.br/eventos/snef/xxi/sys/ resumos/T0629-1.pdf. Acesso em: 5 ago. 2020.

LEIRIA, T. F.; MATARUCO, S. M. C. O Papel das Atividades Experimentais no Processo Ensino-Aprendizagem de Física. Anais do Educere - XII Congresso Nacional de Educação. Curitiba - PR. 2015. Disponível em: https://educere.pucpr.br/pt/. Acesso em: 4 mai. 2020.

LIMA, E. G. Metodologia alternativa para o ensino de Física: experimento de baixo custo em Mecânica. 2019. 50 f. Trabalho de Conclusão de Curso (Licenciatura em Física) - Centro de Ciências, Universidade Federal do Ceará, Fortaleza, 2019

LOPES, R. P. et al. Experimentação real e virtual de circuitos elétricos simples como ferramenta mediadora no processo de aprendizagem de Física. Anais do XVIII Simpósio Nacional de Ensino de Física. Vitória - Espírito Santo. 2009. Disponível em: https://sec.sbfisica.org.br/eventos/snef/xviii/. Acesso em: 12 jul. 2020.

MENDES, M. A.; FIALHO, F. A. P. Experimentação tecnológica prática a distância. Anais do $1^{\circ}$ Congresso Internacional de Educação a Distância. Florianópolis - SC. 2005. Disponível em: http://www.abed. org.br/congresso2005/por/home.htm. Acesso em: 14 mai. 2020.

MONTEIRO, J. C. B. et al. Os ambientes virtuais de aprendizagem (AVA) como fator de motivação no ensino de Física. Anais do XX Simpósio Nacional de Ensino de Física - SNEF. São Paulo - SP. 2013. Disponível em:<https://sec.sbfisica.org.br/eventos/snef/xx/sys/resumos/T0550-1.pdf>. Acesso em: 15 jul. 2020.

MONTEIRO, M. A. A. et al. Experimento controlado remotamente para o estudo da cinemática. Anais do XX Simpósio Nacional de Ensino de Física. São Paulo - SP. 2013. Disponível em: https://sec.sbfisica. org.br/eventos/snef/xx/sys/resumos/T1042-1.pdf. Acesso em: 15 jul. 2020.

MOREIRA, R. M.; MANTILLA, S. P. S. Atividade experimental e simuladores didáticos on-line: impacto na aprendizagem de Física. Anais do $21^{\circ}$ Congresso Internacional de Educação a Distância. Bento Gonçalves - RS. 2015. Disponível em: http://www.abed.org.br/hotsite/21-ciaed/pt/anais/. Acesso em: 14 mai. 2020.

MORO, F. T.; NEIDE, I. G.; VETTORI, M. Atividades experimentais e simulações computacionais: alicerces dos processos de ensino e de aprendizagem da Física no Ensino Médio. Anais do XXI Simpósio Nacional de Ensino de Física. Uberlândia - MG. 2015. Disponível em: https://sec.sbfisica.org.br/eventos/snef/xxi/sys/resumos/T1059-1.pdf. Acesso em 5 ago. 2020. 
NEIDE, I. G.; GAMA JÚNIOR, R. C. Um diagnóstico das publicações sobre a integração das atividades experimentais e computacionais no ensino de Física. Anais do XVII Encontro de Pesquisa em Ensino de Física. Campos do Jordão - SP. 2018. Disponível em: http://www.sbfisica.org.br/ epef/xvii/index.php/ pt/index.html. Acesso em: 15 jul. 2020.

NEVES, J. A. et al. Simuladores como atividades práticas complementares ao laboratório real. Anais do XX Simpósio Nacional de Ensino de Física. São Paulo - SP. 2013. Disponível em: https://sec.sbfisica.org. br/eventos/snef/xx/sys/resumos/T1043-1.pdf. Acesso em: 15 jul. 2020.

NÓBREGA-THIERREN, S.M .; THIERREN, J. Trabalhos Científicos e o Estado da Questão: reflexões teórico-metodológicas. Estudos em Avaliação Educacional, v. 15, n. 30, jul-dez./2004

OLIVEIRA, C. de; MOURA, S.P.; SOUZA, E.R. de. TIC's na Educação: a utilização das tecnologias da informação e comunicação na aprendizagem do aluno. Revista Pedagogia em Ação, v.7, n.1, 2015.

OLIVEIRA, H. S.; FREIRE, M. L. F. . O computador e o ensino de Física: simulação e modelagem computacional. Revista Compartilhando Saberes, v. 1, p. 40, 2014.

PEREIRA, M. V. et al. Demonstrações experimentais de Física em formato audiovisual produzidas por alunos do Ensino Médio. Caderno Brasileiro de Ensino de Física, v. 28, p. 676-692, 2011.

PESSANHA, M. C. R; COZENDEY, S. G.; SOUZA, M. O. Interação entre luz e matéria: um experimento com acesso a distância através da Internet. Anais do XVIII Simpósio Nacional de Ensino de Física. Vitória - ES. 2009. Disponível em: <https://sec.sbfisica.org.br/eventos/snef/xviii/programa/lista trabalho. asp?sesld=23>. Acesso em: 15 jul.2020.

PONTONE JUNIOR, R.; PAULA, H. F. Caracterização geral do uso de simulações e laboratórios virtuais em uma sala de aula de Física. Anais do XVII Encontro de Pesquisa em Ensino de Física. Campos do Jordão-SP. 2018. Disponível em: <https://sec.sbfisica.org.br/eventos/epef/xvii/programa/trabalhos.asp?sesld=39>. Acesso em: 15 jul.2020.

RUAS, F. P. et al. Formação Online de professores de ciências: a construção de modelos explicativos com vistas a compreensão de fenômenos. In: KRAUSE, J.C et al.(org.). Formação docente e educação científica. Cruz Alta: llustração, 2020. p.229-240.

SALES, G. L.; LEITE, E. A. M; VASCONCELOS, G. H. L. TDIC como suporte à aprendizagem de física no Ensino Médio. Anais do XXI Simpósio Nacional de Ensino de Física. Uberlândia - MG. 2015. Disponível em: https://sec.sbfisica.org.br/eventos/snef/xxi/sys/resumos/T0006-1.pdf. Acesso em: 2 ago. 2020.

SANTOS, J. C. dos. et al. Conciliando experimento e simulação computacional no ensino de queda livre. Anais do XXII Simpósio Nacional de Ensino de Física. São Carlos - SP. 2017. Disponível em: https:// sec.sbfisica.org.br/eventos/snef/xxii/sys/resumos/T0604-1.pdf. Acesso em 15 ago. 2020.

SCHUCK, A. F.; SERRANO, A. Um exemplo do uso de experimentos virtuais objetivando a introdução de conceitos de mecânica quântica na disciplina de estrutura da matéria. IX Encontro de Pesquisa em Ensino de Física. Jaboticabaus - MG. 2004. Disponível em: https://sec.sbfisica.org.br/eventos/epef/ix/. Acesso em: 15 jul. 2020.

SENA, M.; SILVA, R.; MARTINS, A. Oficina de experimentos virtuais de física para o Ensino Médio. Anais do XVI Encontro de Pesquisa em Ensino de Física. Natal - RN. 2016. Disponível em: http://sbfisica.org. br/ fisica2016/. Acesso em: 11 set. 2020.

SILVA, N. C. da. Laboratório virtual de Física Moderna: simulações para seis arranjos experimentais. Anais do XX Simpósio Nacional de Ensino de Física. São Paulo - SP. 2013. Disponível em: https://sec.sbfisica.org.br/eventos/snef/xx/sys/resumos/T0471-1.pdf. Acesso em: 15 jul. 2020. 
SILVA, T. da. Um material didático hipermídia para o ensino de fenômenos astronômicos. Anais do XVII Simpósio Nacional de Ensino de Física. São Luís - MA. 2007. Disponível em: https://sec.sbfisica.org. br/eventos/snef/xvii/atas/resumos/T0503-1.pdf. Acesso em: 15 jul. 2020.

SILVA, M. J. V. T. da; ANGOTTI, J. A. P.; MION, R. A. Revitalizar laboratórios para ensinar física: possibilidades dos softwares de autoria em atividades teórico-experimentais. Anais do XI Encontro de Pesquisa em Ensino de Física. Curitiba - PR. 2008. Disponível em: https://sec.sbfisica.org.br/eventos/epef/xi/ resumo.shtml. Acesso em: 11 set. 2020.

SILVA, T. da; BARROSO, M. F. Fenômenos astronômicos e ensino a distância: produção e avaliação de materiais didáticos. Anais do XI Encontro de Pesquisa em Ensino de Física. Curitiba - PR. 2008. Disponível em: https://sec.sbfisica.org.br/eventos/epef/xi/resumo.shtml. Acesso em: 11 set. 2020.

SILVA, J. C. et al. Usos de simulações em aulas de física: o fazer e o refletir de equipe do PIBID Física UFMG. Anais do XXI Simpósio Nacional de Ensino de Física. Uberlândia - MG. 2015. Disponível em: https:// sec.sbfisica.org.br/eventos/snef/xxi/sys/resumos/T0569-2.pdf. Acesso em: 5 ago. 2020.

SILVA, C.F. da. et al. Atividade virtual de física em escolas de Rondônia. Anais do XIV Encontro de Pesquisa em Ensino de Física. Maresias - SP. 2012. Disponível em: <https://sec.sbfisica.org.br/eventos/epef/ xiv/sys/resumos/T0137-1.pdf >. Acesso em: 15 jul.2020.

SIM, A. A. do; MONTEIRO, M. A. A. Experimento remoto como ferramenta de aprendizagem: um estudo comparativo. Anais do XXII Simpósio Nacional de Ensino de Física. São Carlos - SP. 2017. Disponível em: https://sec.sbfisica.org.br/eventos/snef/xxii/sys/resumos/T0426-1.pdf. Acesso em 15 ago. 2020.

SOUZA, G. L. de et al. Experimentação Remota no Ensino de Física. Anais do XV Simpósio Nacional de Ensino de Física. Curitiba - PR. 2003. Disponível em: https://sec.sbfisica.org.br/eventos/snef/xv/. Acesso em: 22 jul. 2020.

SOUZA, C. P. de; COSTA FILHO, J. T. Laboratório a distância - um novo recurso na educação a distância. Anais do $8^{\circ}$ Congresso Internacional de Educação a Distância. Brasília - DF. 2001. Disponível em: http://www.abed.org.br/congresso2001/. Acesso em: 14 mai. 2020.

STEIN-BARANA, A. C. de M.; LOPES, D. P. M. Temas de Física no ensino de Ciências: formação continuada a distância de professores do primeiro ciclo do Ensino Fundamental associada à inclusão digital. Anais do XI Encontro de Pesquisa em Ensino de Física. Curitiba - PR. 2008. Disponível em: https://sec. sbfisica.org.br/eventos/epef/xi/resumo.shtml. Acesso em: 11 set. 2020.

TORI, R.. Educação sem distância: As Tecnologias Interativas na Redução de Distâncias em Ensino e Aprendizagem. 1. ed. São Paulo: Editora Senac São Paulo, v. 1. 256p. 2010.

XAVIER, A. P.; VERTCHENKO, L.; AMANTES, A. Atividade prática associada à simulação computacional para o ensino de conceitos de hidrodinâmica. Anais do XXI Simpósio Nacional de Ensino de Física. Uberlândia - MG. 2015. Disponível em: https://sec.sbfisica.org.br/eventos/snef/xxi/sys/resumos/T0954-1. pdf. Acesso em: 2 ago. 2020. 